\title{
Modelling heterogeneity of concrete using 2D lattice network for concrete fracture and comparison with $\mathrm{AE}$ study
}

\author{
R VIDYA SAGAR* and B K RAGHU PRASAD \\ Department of Civil Engineering, Indian Institute of Science, Bangalore 560012 \\ e-mail: rvsagar@civil.iisc.ernet.in
}

MS received 10 April 2008; revised 25 November 2008

\begin{abstract}
In this paper, numerical modelling of fracture in concrete using two-dimensional lattice model is presented and also a few issues related to lattice modelling technique applicable to concrete fracture are reviewed. A comparison is made with acoustic emission (AE) events with the number of fractured elements. To implement the heterogeneity of the plain concrete, two methods namely, by generating grain structure of the concrete using Fuller's distribution and the concrete material properties are randomly distributed following Gaussian distribution are used. In the first method, the modelling of the concrete at meso level is carried out following the existing methods available in literature. The shape of the aggregates present in the concrete are assumed as perfect spheres and shape of the same in two-dimensional lattice network is circular. A three-point bend (TPB) specimen is tested in the experiment under crack mouth opening displacement (CMOD) control at a rate of $0.0004 \mathrm{~mm} / \mathrm{sec}$ and the fracture process in the same TPB specimen is modelled using regular triangular 2D lattice network. Load versus crack mouth opening displacement (CMOD) plots thus obtained by using both the methods are compared with experimental results. It was observed that the number of fractured elements increases near the peak load and beyond the peak load. That is once the crack starts to propagate. AE hits also increase rapidly beyond the peak load. It is compulsory here to mention that although the lattice modelling of concrete fracture used in this present study is very similar to those already available in literature, the present work brings out certain finer details which are not available explicitly in the earlier works.
\end{abstract}

Keywords. Concrete fracture; lattice model; Fuller distribution; acoustic emission; acoustic emission energy; crack mouth opening displacement.

\section{Introduction}

Research studies related to developments in new materials have resulted in composites which have a soft matrix, weak in tension reinforced with brittle harder particles embedded. Such composites are neither plastic nor brittle but these composites response under uni-axial stress

*For correspondence 
condition is somewhere in between and thus they are called quasi-brittle materials. A few examples are cement mortar and concrete in civil engineering. Based on the tensile stressdeformation response, most engineering materials are classified into brittle, ductile, or quasibrittle type materials. Such a quasi-brittle material like concrete is characterized by a gradually decreasing stress after peak stress (Bazant 1998; Karihaloo 1995; Shah et al 1995). It is known that concrete, which is heterogeneous at the meso scale $\left(10^{-4} \mathrm{~m}\right.$ to $\left.10^{-2} \mathrm{~m}\right)$, exhibit strain softening behaviour and fails progressively by damage-localization (VanMier 1997). It is also known that one of the main characteristics of quasi-brittle materials like concrete is its heterogeneity and due to this cracks are tortuous. Concrete is an important construction material and studies related to fracture process in concrete has been the subject of research (Bazant 1998; Karihaloo 1995; Shah et al 1995). The phenomenon of cracking is the most important feature of the concrete behaviour. For interpreting and designing of laboratory experiments and to study the fracture process in concrete, the lattice model is quite useful and the details about the lattice model are well-documented (Van Mier 1997).

\section{Aim and objectives of the present study}

A regular triangular lattice of beam elements is used to model fracture processes in plain cement concrete. In the present study, the heterogeneity in the concrete medium is modelled by two methods viz. (i) projecting the two-dimensional lattice network of beam elements on grain/particle structure of the plain concrete following Walraven (1980) and Schlangen \& Van Mier (1992a, 1992b). (ii) By assigning varying tensile strengths and stiffnesses to the lattice members following normal (Gaussian) distribution. During fracture, lattice element properties are systematically modified to simulate the fracture process in concrete. In this study, concrete is modelled at the meso-level $\left(10^{-4} \mathrm{~m}\right.$ to $10^{-2} \mathrm{~m}$ ) (figure 1 ) using the above two methods. A comparison was made with acoustic emission (AE) parameter with the number of fractured elements. Because it would allow to better understand the capability of the lattice model in predicting the formulation of micro-cracks, both in the pre-peak and in the post-peak regime.

\section{The lattice model}

As mentioned previously, in the lattice model a technique is used which has received much attention in theoretical physics. But the basic idea related to lattice model is an older concept. Concrete is a porous composite material consisting of sand and coarse aggregates embedded in a cement paste matrix. The pores in the material play an essential role in strength, ductility and durability. Researchers in the field of fracture mechanics of concrete modelled concrete in three level approaches. These are micro, meso and macro levels. The meso-level considers the composite nature of concrete and distinguishes among hardened cement paste, aggregate, and a bond layer between cement paste and aggregate constituents as shown in figure 1 . Disorder must be taken into account when a heterogeneous material like concrete is simulated (VanMier 1997).

Numerical simulation connected with theory and experiment is considered to be a tool for further material development (Schlangen \& Van Mier 1991, 1992; Schlangen 1993, Schlangen \& Garboczi 1996, 1997; VanMier 1997). The concept of the lattice model is discretization of the continuum by line elements such as bar elements or beam elements, which can transfer forces and moments (Schlangen \& Van Mier 1991, 1992a, 1992b). In general, 
lattice network with truss elements corresponds to the classical continuum. But in case of a lattice with beam elements corresponds to the micro polar continuum (Ince 2005; Karihaloo et al 2003). By using the lattice model technique it is possible to identify micro cracking, crack branching, crack tortuosity and bridging. The earliest lattice model was proposed by Hrennikoff, who introduced a regular triangular lattice of truss elements to solve classical problems in elasticity (Hrennikoff 1941). Numerical modelling of concrete fracture studied by Wittmann and co-workers has shown encouraging results (Roelfstra et al 1985).

The mechanical behaviour of concrete was analysed numerically by a particle model (Sadouki \& Van Mier 1997). Over the last several years lattice models have been used for various applications. Burt \& Dougil (1977) modelled a progressive failure in heterogeneous material. The brittle failure of disordered materials and the conductivity of the materials using a square lattice with beam elements was carried out by Herrmann et al (1989) and proposed a triangular lattice with elements of random length (Herrmann 1991; Herrmann et al 1989). A report on experimental and numerical analysis of micro mechanisms of fracture of cement based composites and simulated a concrete plate with a notch using beam elements was prepared (Schlangen \& Van Mier 1992). Schlangen \& Van Mier (1992a,b; 1993a,b) simulated the fracture in concrete materials with triangular lattice with beam elements. Schlangen $\&$ Garboczi (1997) showed that local rotations at the nodes play an important role in the simulated fracture process. The computation aspects of simulations of fracture in concrete and other quasi brittle materials using lattice technique was carried out (Schlangen \& Garboczi 1996, 1997). Experimental and numerical investigation on the fractal properties of particle composites was performed (Chiaia et al 1997). Van Mier \& Van Vliet (2003) investigated the influence of microstructure of concrete on size/scale effects in tensile fracture. Effect of particle structure on mode I fracture process in concrete was studied by Prado \& Van Mier (2003). The size effect in concrete was modelled by lattice technique by considering the tension softening of matrix phase using beam elements in the lattice (Ince et al 2003) and in the same study regular square lattice model was used to simulate concrete fracture and the improvements pertaining to the inclusion of the tension softening response of the matrix phase, and the modelling of structural response by incrementing the deformation rather than the load was used (Arslan et al 2002). Particle composites using lattice model with beam elements based on the Timoshenko theory was modelled (Karihaloo et al 2003). For simulating fracture process in heterogeneous material such as in plain concrete disorder has to be implemented. A novel meso-mechanical approach for modelling concrete fracture which uses the composite material model with distributed-phase for elastic properties of all three phases and also considered the size effect in concrete was developed (Ince 2005). 3D analysis of fracture process in concrete was carried out using lattice models (Lilliu \& Van Mier 2003, Lilliu \& Van Mier 2007, Lilliu 2007).

\section{Different procedures for implementing heterogeneity of the concrete medium}

The heterogeneity of the concrete medium can be incorporated in a lattice model using two different approaches, one is randomly distributed material properties and the second is generating the grain structure using Fuller's distribution (Walraven 1980).

\subsection{Randomly distributed concrete properties}

The disorder in concrete medium can be represented by assigning different strengths and or stiffnesses to the lattice members following a particular probability distribution 


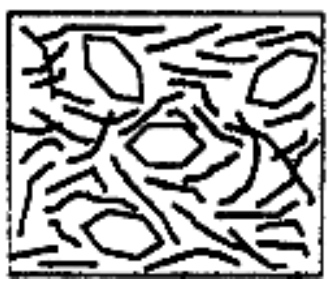

(a)

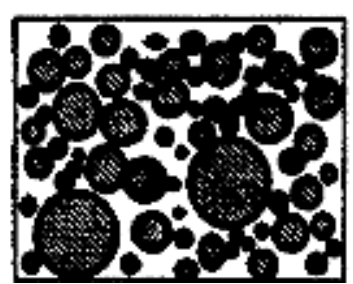

(b)

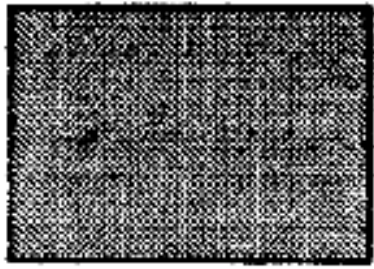

(c)

Figure 1. Three level approach according to Wittmann (1983); (a) micro level [10 $10^{-8} \mathrm{~m}$ to $\left.10^{-4} \mathrm{~m}\right]$, (b) meso level $\left[10^{-4} \mathrm{~m}\right.$ to $\left.10^{-2} \mathrm{~m}\right]$, (c) macro level $\left[10^{-1} \mathrm{~m}\right.$ to $10^{-2} \mathrm{~m}$ ] (VanMier 1997).

(VanMier 1997). In the present study, normal distribution is used to randomly distribute the material properties to all the lattice members present in lattice network. Where the random variable is the material property like modulus of elasticity $(E)$ and tensile strength $\left(\sigma_{t}\right)$. In the present study only $E$ is considered. The model is capable of considering any number of random values to simulate the heterogeneity of concrete. In the present study, the material properties to the lattice members assigned following the Normal distribution (Gaussian distribution). The Young's modulus ' $x$ ' of a lattice member is assumed to follow a normal or Gaussian distribution as given below

$$
f_{x}(x)=\frac{1}{\sqrt{2 \pi \sigma^{2}}} e^{\frac{-(x-\mu)^{2}}{2 \sigma^{2}}}
$$

$\sigma=$ standard deviation

$\mu=$ mean

$x=$ lattice member's young's modulus or the lattice member's 'tensile strength'.

Figure 2 shows the distribution of tensile strengths of the lattice members and young's modulus of the lattice members following (1).

\subsection{Modelling of the plain concrete using generated grain structure}

In the present study, heterogeneous structure of concrete is modelled at meso scale in the region (middle $1 / 3^{\text {rd }}$ span of the TPB specimen) where the fracture is expected. The rest of the region of the TPB specimen modelled with finite element mesh $\left(E=30000 \mathrm{~N} / \mathrm{mm}^{2}\right.$ and $v=0.2$ ). Within the lattice region, the heterogeneity is modelled clearly by assigning different material properties to different elements within the lattice structure. In this study the authors assumed that concrete is a three-phase quasi-brittle material namely coarse aggregate particles, the matrix of sand and hardened cement paste, and the interface transition zone, or bond zone (figures 1 and 5) which are shown in figure 1b. The material model of the lattice elements is in all three cases a linear elastic, brittle but with different properties for each phase material. The linear elastic material model only needs Young's modulus $E$. In literature it was cited that it is difficult to determine the value of the Young's moduli for each phase. Vervuurt (1997) studied the material properties of each phase and their ratios. The Poisson's ratio of the material determines the height of the lattice elements. Earlier researchers derived a relationship between poison's ratio of concrete and ratio (length/depth) of the lattice members 

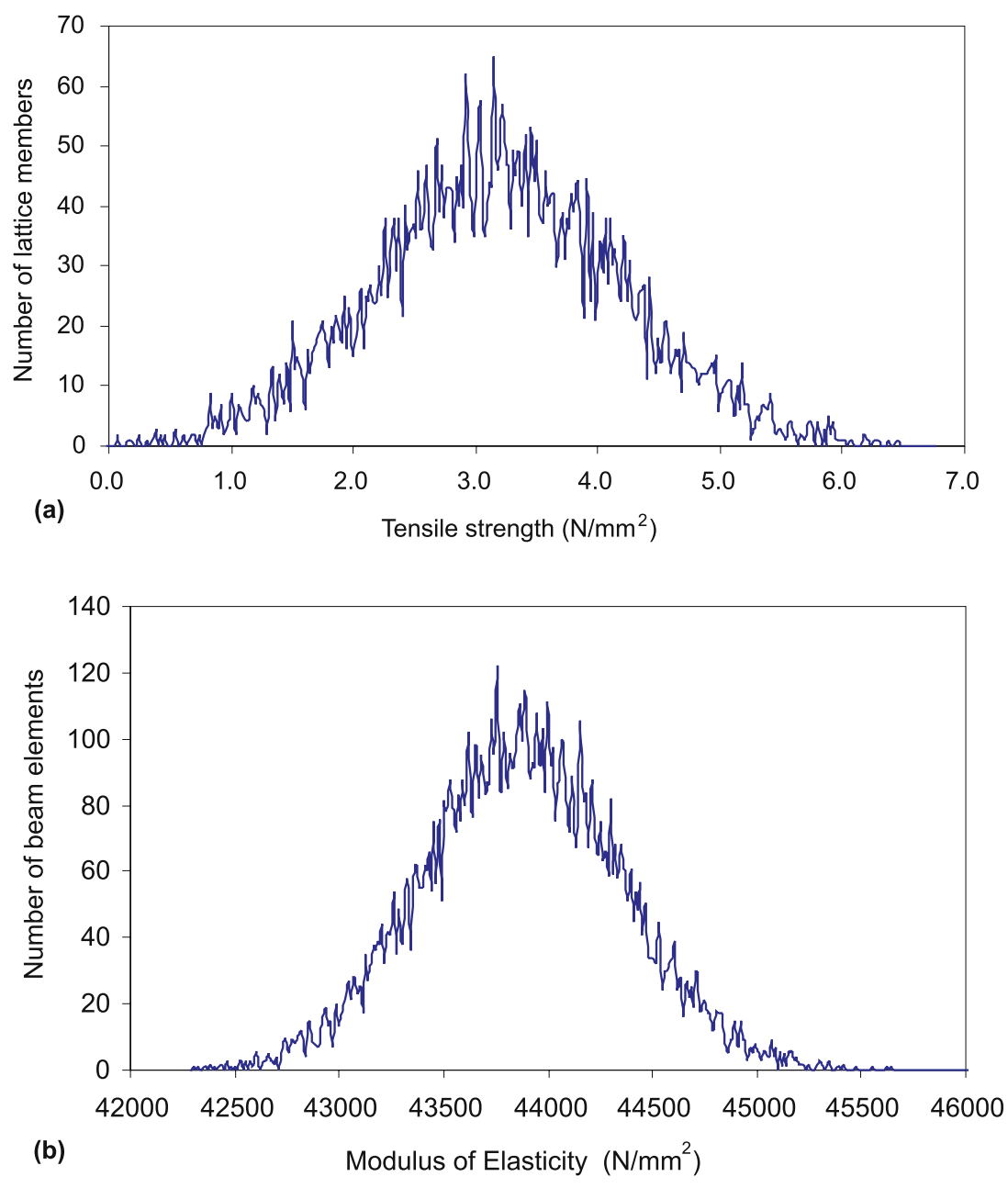

Figure 2. Gaussian distribution of (a) lattice members tensile strength, (b) lattice members modulus of elasticity [note: In case of modulus of elasticity, $\mu=15913.84 \mathrm{MPa}$ and $\sigma=477.415 \mathrm{MPa}$ ].

(Schlangen \& Garboczi 1997; Vanvliet 2000).

$$
v=\frac{1-\left(\frac{h}{l}\right)^{2}}{3+\left(\frac{h}{l}\right)^{2}} .
$$

In (2) $l$ is the length of the lattice element which is constant in a regular triangular lattice structure. Equation (2) represents a relationship between (depth/length) of beam element and Possion's ratio of concrete. In the present study, a physically realistic Poisson's ratio equal to 0.2 is assumed. The ratio between the depth of the lattice member to its length $(h / l)$ is 0.5772 . It is clear that the concrete behaviour is modelled by the lattice elements both by the material model of the lattice elements with the Young's modulus $E$ and the height of the lattice beam element which is a geometry property. The width of the lattice element is taken as equal to the width of the TPB specimen tested and it is $80 \mathrm{~mm}$ in the present study. Here the authors 
Table 1. Matériel properties (Alexander et al 1968; Ince et al 2003).

\begin{tabular}{lcccc}
\hline & $\begin{array}{c}\text { Young's } \\
\text { modulus } \\
\left(\mathrm{N} / \mathrm{mm}^{2}\right)\end{array}$ & $\begin{array}{c}\text { Tensile } \\
\text { strength } \\
\left(\mathrm{N} / \mathrm{mm}^{2}\right)\end{array}$ & \multicolumn{2}{c}{$\begin{array}{c}\text { Cross sectional properties } \\
\text { of the Beam element }\end{array}$} \\
\cline { 4 - 5 } & 75000 & $10 \cdot 0$ & Depth $(\mathrm{mm})$ & Width $(\mathrm{mm})$ \\
\hline Aggregate & 25000 & $5 \cdot 0$ & 1.443 & 80 \\
Matrix & 25000 & $2 \cdot 5$ & 1.443 & 80 \\
Bond & & & & 80 \\
\hline
\end{tabular}

assumed the material properties for each phase and are indicated in table 1 . The material properties of the lattice elements depend on whether the lattice element models an aggregate particle, the matrix, or the bond zone between the particle and the matrix. The determination of the material behaviour of a lattice element is performed by applying an overlay technique in which a generated particle structure is mapped onto the lattice structure. The generated particle structure is shown in figure 3. The algorithm determines the position of the lattice element in relation to the overlay and the same was shown in figure 4 . If both nodes of the

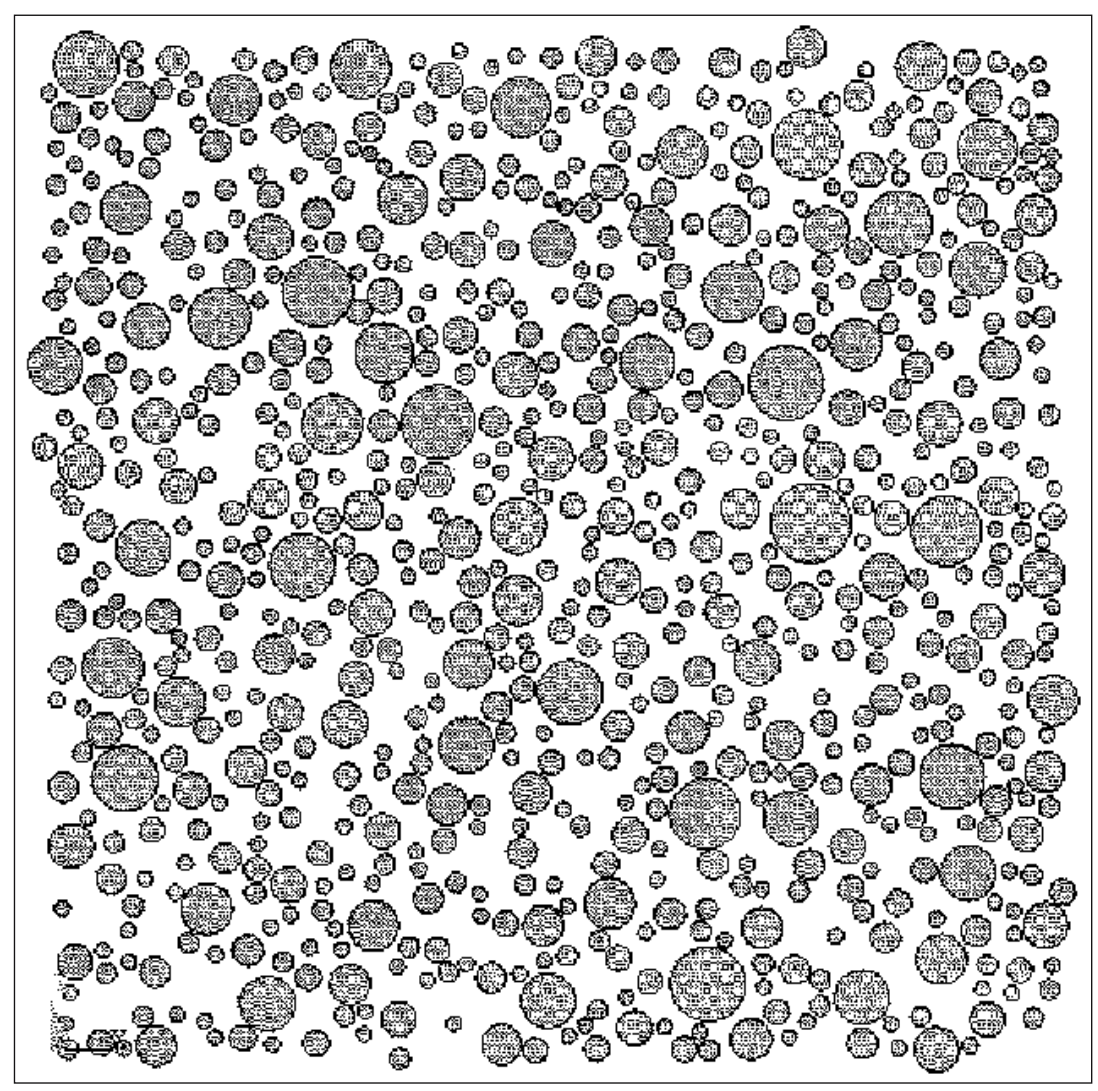

Figure 3. Generated particle structure of concrete following Fuller distribution and the cumulative distribution function equation (Walraven 1980; Schlangen \& Garboczi 1997). 


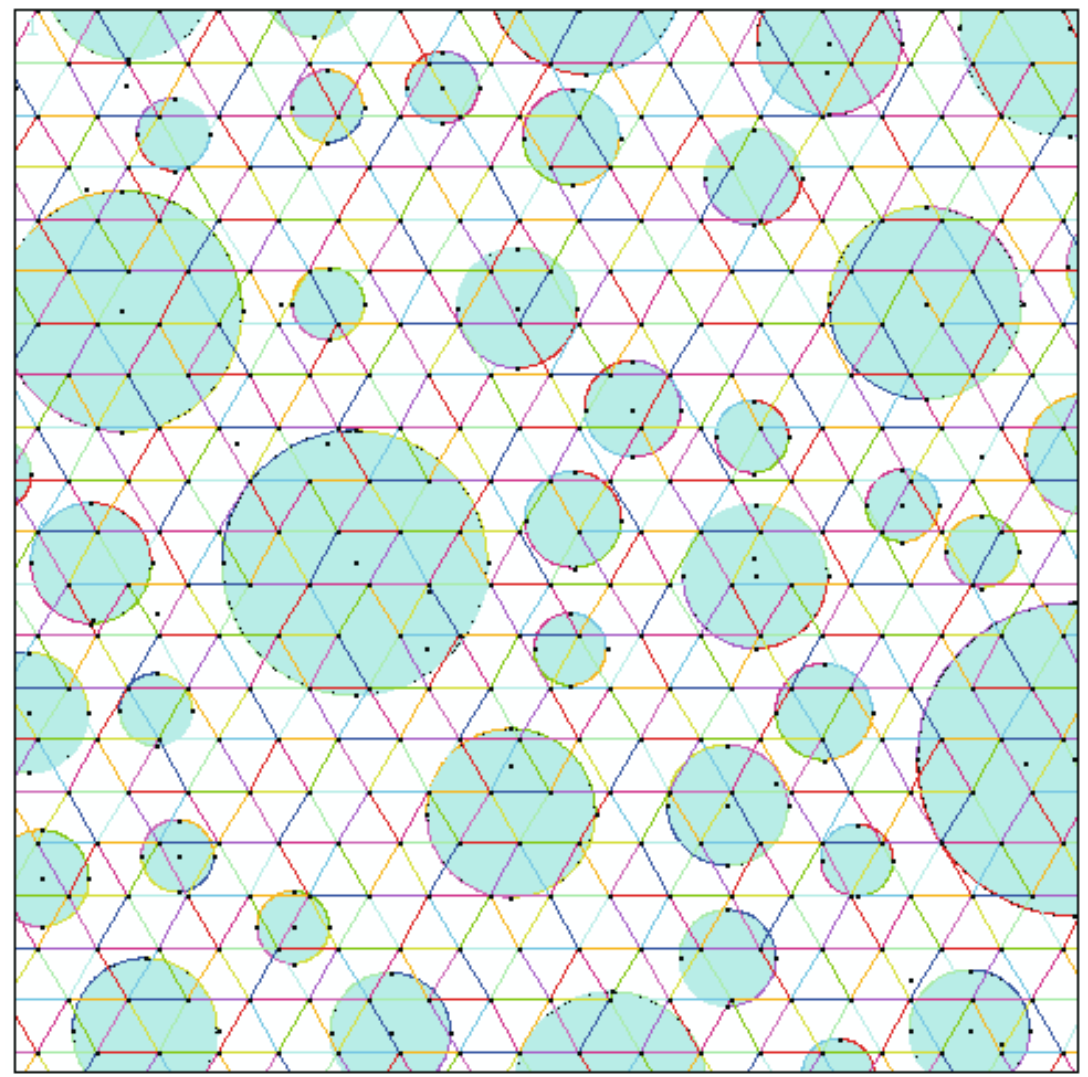

Figure 4. Triangular lattice projected on top of a generated particle structure of concrete.

lattice element are within the same particle, the element aggregate matrix is assigned to the material properties of an aggregate particle. If both nodes of the lattice element are located outside a particle, the material properties of the matrix are assigned to the lattice element. In other cases the lattice element models the bond zone and the material properties of the bond zone are assigned to the corresponding lattice element. Figure 5 shows the assigning procedure of different properties to the lattice members. The particle structure which is used as the overlay structure is generated according to a Fuller's distribution. The Fuller curve is given by the percentage by weight passing a sieve with aperture diameter $D$ of a cement concrete mix with a maximum aggregate diameter $D_{\max }$ (Walraven 1980, VanMier 1997),

$$
p=100 \sqrt{\frac{D}{D_{\max }}} .
$$

Equation (3) represents the description of the Fuller curve in which $p$ denotes the percentage by weight passing a sieve with aperture diameter $D$ and $D_{\max }$ is the diameter of the maximum size of the particle. Earlier researchers used (3) as the cumulative distribution function of spherical aggregate particles with a diameter $D$. In this study, the coarse aggregates present in the concrete are assumed as spheres. The curve shown in figure 6 represents a grading of aggregate particles which results in optimum density and strength of the concrete mix. 


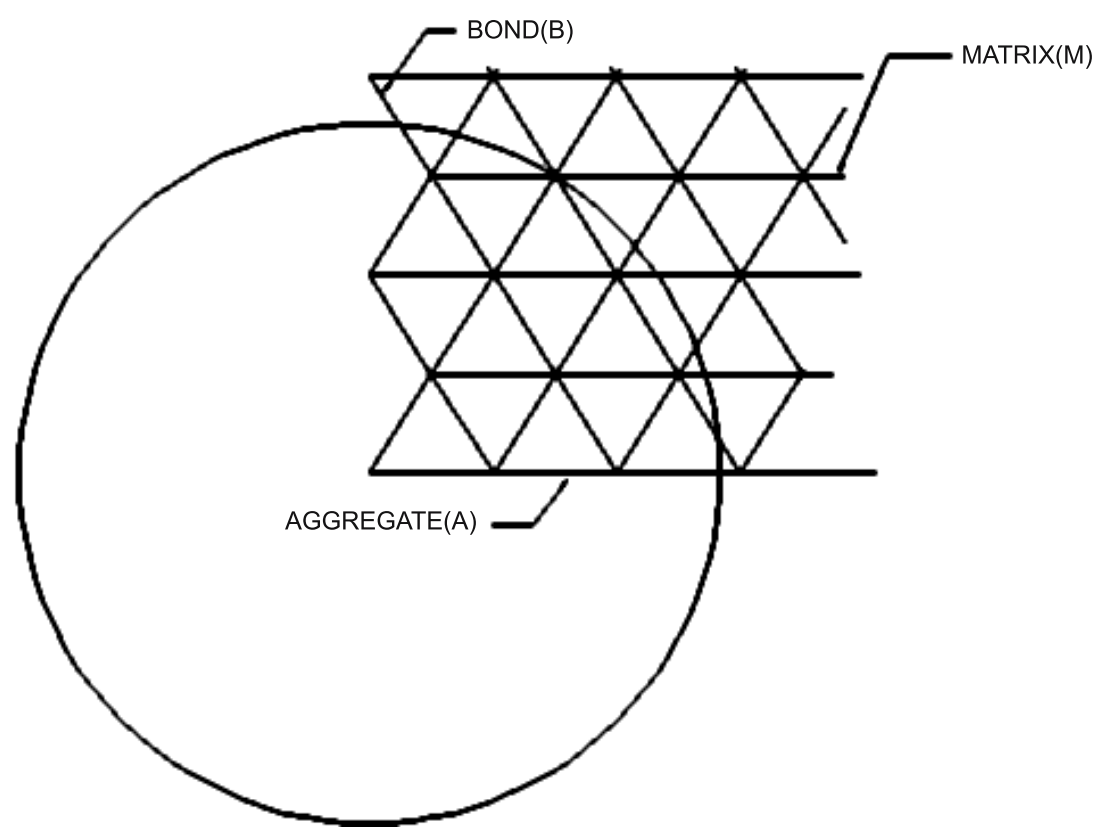

Figure 5. Assigning different properties to the lattice members i.e. aggregate, matrix and bond (Van Mier 1997).

Using the Fuller's distribution theory, Walraven (1980) derived an expression to represent aggregates distribution in 2D plane: This expression represents the determination of the most probable distribution of diameters of the intersection circles, which are located in a $z$-plane and are crossed by the crack (Walraven 1980). For a given concrete mix, the distribution of circle diameters in a certain cross section can be generated. The cumulative distribution function for a concrete mix which represents the probability $P_{c}$ that an arbitrary point in the concrete body,

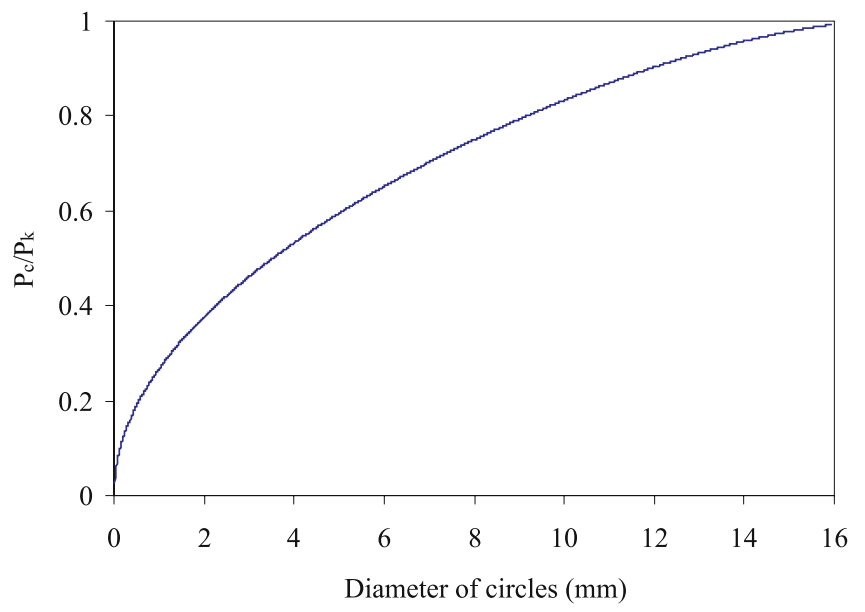

Figure 6. Cumulative distribution function for the diameter of intersection circles in a plane based on a Fuller particle size distribution (Walraven 1980). [Note: $P_{c}=$ the probability that an arbitrary point in a concrete body, lying in an intersection plane, is located in an intersection circle with a diameter $d<d_{0} ; P_{k}$ is ratio between volume of coarse aggregate particles to total volume of concrete. In this plot the maximum size of aggregate is $16 \mathrm{~mm}$ ]. 
lying in an intersection plane is located in an intersection circle (Walraven 1980, VanVliet 2000) with a diameter $D<D_{0}$.

$$
\begin{aligned}
P_{c}\left(D<D_{0}\right)= & P_{k}\left[1.065\left(\frac{D_{0}}{d_{\max }}\right)^{0.5}-0.053\left(\frac{D_{0}}{d_{\max }}\right)^{4}-0.012\left(\frac{D_{0}}{d_{\max }}\right)^{6}\right. \\
& \left.-0.0045\left(\frac{D_{0}}{d_{\max }}\right)^{8}-0.0025\left(\frac{D_{0}}{d_{\max }}\right)^{10}\right]
\end{aligned}
$$

$D_{0}=$ sieve size

$P_{c}(D)=$ Probability of the existence of an aggregate particle of size $D$

$d_{a}=$ maximum aggregate size

$p_{k}=$ aggregate volume fraction (usually the value of $p_{k}$ is 0.75 ).

$P_{k}$ is the ratio of the aggregate volume to the total volume of the concrete. In fact (4) represents the Fuller grading curve in two-dimensions (Walraven 1980). Figure 6 shows the cumulative distribution function for the diameter of intersection circles in a plane based on a Fuller particle size distribution. For a given area $A$ and aggregate fraction $P_{k}$, the number of aggregate particles $n_{i}$ with diameter $d_{i}$ can be obtained (Van Vliet 2000) from (5a) and (5b).

$$
\begin{aligned}
& n_{i}=\frac{\left[p_{c}\left(d<d_{i}+0.5\right)-p_{c}\left(d<d_{i}-0.5\right)\right] A P_{k}}{0 \cdot 25 \pi d_{i}^{2}} \quad d_{i}<d_{\max } \\
& n_{i}=\frac{\left[p_{c}\left(d<d_{i}\right)-p_{c}\left(d<d_{i}-0.5\right)\right] A P_{k}}{0.25 \pi d_{i}^{2}} \quad d_{i}=d_{\max }
\end{aligned}
$$

The particles are placed in a two-dimensional area from which the required particle structure is selected. For an area of $200 \mathrm{~mm} \times 200 \mathrm{~mm}$ the generated circles are given in table 2 . In literature it was well cited about several methods for placing the particles (Schlangen \& Garboczi 1997). In the present study, particles are randomly placed by calculation of the $x$ coordinate and the $y$ coordinate of centre a circle with diameter $D$. The algorithm developed by authors first places the particles with the largest diameters and continues with decreasing diameters. The condition for placement of the aggregates is that the distance between two aggregates $A$ and $B$ has to be equal, or larger than $X_{0}$ following the (6) (Hsu \& Slate 1963; Schlangen \& Van Mier 1992; Schlangen \& Garboczi 1997).

$$
X_{0}=1 \cdot 1\left[\frac{\left(d_{A}+d_{B}\right)}{2}\right] \text {. }
$$

Figure 3 shows the generated particle structure of concrete and $X_{0}$ is the distance between the two circle centers. The next step is to overlay the generated grain particle structure with

Table 2. Distribution of circles in the $2 \mathrm{D}$ plane.

\section{Distribution of circles}

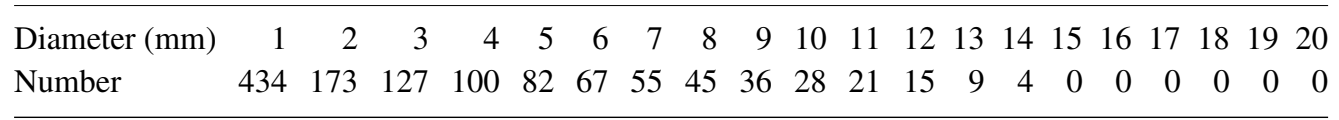


a lattice. In figure 4 a generated regular triangular lattice is projected on top of a material structure. As mentioned previously, lattice members whose both ends falling inside the circular aggregate particle are assigned with aggregate properties. Matrix properties are assigned to those lattice members falling inside the matrix material, and bond properties are assigned to the members falling over the boundary of the circular aggregate. In this model, the material is schematized as a lattice of brittle breaking beam elements. Material properties, which must be assigned are the Young's moduli and tensile strengths. The dimensions of the specimen used for the analysis are given in table 3. A TPB specimen meshed with lattice beam elements is shown in figure 7. Only at middle third of the specimen represented with more number of lattice elements. Because cracking was expected to propagate in this region. The other parts of the specimen are modelled with a coarse mesh.

\section{Method of analysis}

A computer program for analysis of lattice structure has been developed. Fracture is simulated by performing a linear elastic analysis of the lattice and removing an element from the mesh that exceeds maximum tensile strength of the element table 1 . The displacement control method was adopted for loading the structure. In the present study, the analysis was carried out on a model consisted of regular triangular lattices with beam elements. In this model, the lattice consists of two node beam elements which have three degrees of freedom at each node i.e. $U_{x}$, $U_{y}$ and $\theta_{z}$. In each step of the fracture analysis the lattice mesh is loaded by external prescribed displacements. For displacement simulation, the prescribed displacement $0.065 \mathrm{~mm} / \mathrm{step}$ is imposed as a constraint in the downward $Y$-direction and the simulation is static. A typical TPB test specimen with lattice members was shown in figure 7. A total number of 1954 nodes and total number of 5679 beam elements ( 2 nodes) were used to model the TPB specimen with

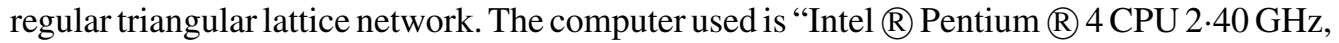
$2.39 \mathrm{GHz}, 1.0 \mathrm{~GB}$ RAM. Gaussian elimination method which is a direct method is used for the solution of the simultaneous equations (William et al 1998). A flow-chart of the implementation procedure is given in figure 8 . The $Y$-direction displacement of the nodes located at the model's left and right supports are kept at zero value. The central node at the top was then subjected to a vertical displacement of $0.065 \mathrm{~mm} /$ iteration in downward $Y$-direction. The analysis of concrete fracture process consists of a series of steps. Each element stress is calculated and checked against the corresponding limiting stress. The limiting stress value for aggregate, matrix and bond are given in table 1 . In case the lattice mebmer's stress reach the limiting values, the corresponding member is considered as fractured element and a negligible value of modulus of elasticity for corresponding fractured element was ascribed in the next load step.

\section{Failure criteria for lattice members}

When performing a fracture analysis on a lattice mesh, a failure criterion has to be chosen. Different criteria for fracture have been adopted and can be found in the literature (Schlangen \& Garboczi 1997). The criterion adopted is that after the limiting value of strength is reached, the stress in the lattice member decreases. Herrmann et al simulated the fracture of metals using a square lattice and assumed that each individual elements in the lattice fail according to the Von Mises' failure criterion (Herrmann 1991; Herrmann et al 1989). However, the 


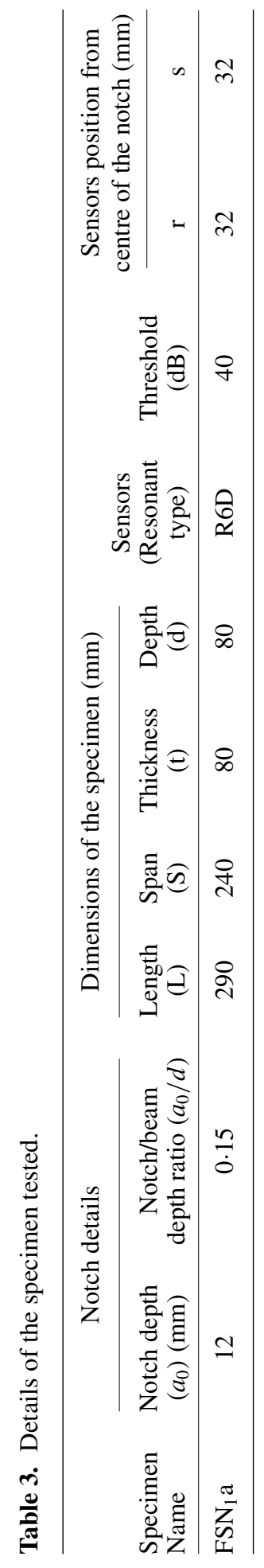




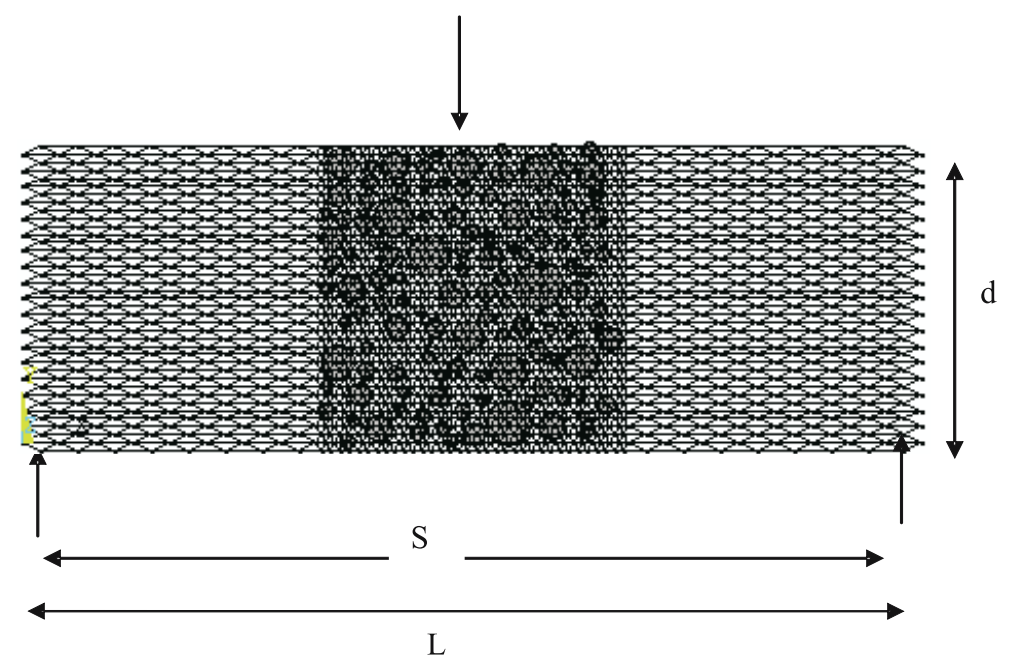

Figure 7. Representing beam with lattice members $(\mathrm{L}=$ length of the beam, $\mathrm{S}=$ span of the beam and $\mathrm{d}=$ depth of the beam).

reported results are not related to concrete fracture. In the present study, it was assumed that failure criterion is the maximum tensile strength of the lattice member. The linear elastic brittle failure behaviour is assumed for aggregate, bond and matrix members present in the lattice network. Once the lattice member's stress exceeds the limiting tensile stress values (table 1) it was assumed that the lattice member failed.

$$
\sigma_{t}<\frac{f}{A}+\frac{\left(\left|M_{i}\right|,\left|M_{j}\right|\right)_{\max }}{W} .
$$

The tensile strength of the element is denoted as $\sigma_{t}$. The axial force $f$ in each lattice element and the bending moments $M_{i}$ and $M_{j}$ in node $i$ and node $j$ respectively are calculated during the linear elastic analysis of the structure. $A$ is the cross sectional area and $W$ is sectional modulus of the lattice member. The material models used in the present study are shown in figure 9. The failure criterion adopted in this study resembles Rankine criterion. A fracture law given in equation (7) was used for beam models by Schorn \& Rode (1987, 1991). The limiting stresses have been assumed as failure criteria. In this study whenever the stress in a member reaches limiting stress, the modulus of elasticity of that member was reduced to negligible value for the next load step, so that cracking takes place. In this study crack growth is simulated by assigning the very small Young's modulus value to the fracture elements. The maximum stress, resulting from the combined normal force and bending moments, is used in the evaluation of a fracture law. The execution of the computer program related to the $2 \mathrm{D}$ lattice model (for the TPB specimen used in the present study) took about one minute using a computer with Intel Pentium 4 processor with 1 GB RAM.

\section{Application of $\mathrm{AE}$ technique to concrete structures}

Although acoustic emission technique is a well established non destructive testing (NDT) method and several books and manuals dealt about the acoustic emission (AE) testing 


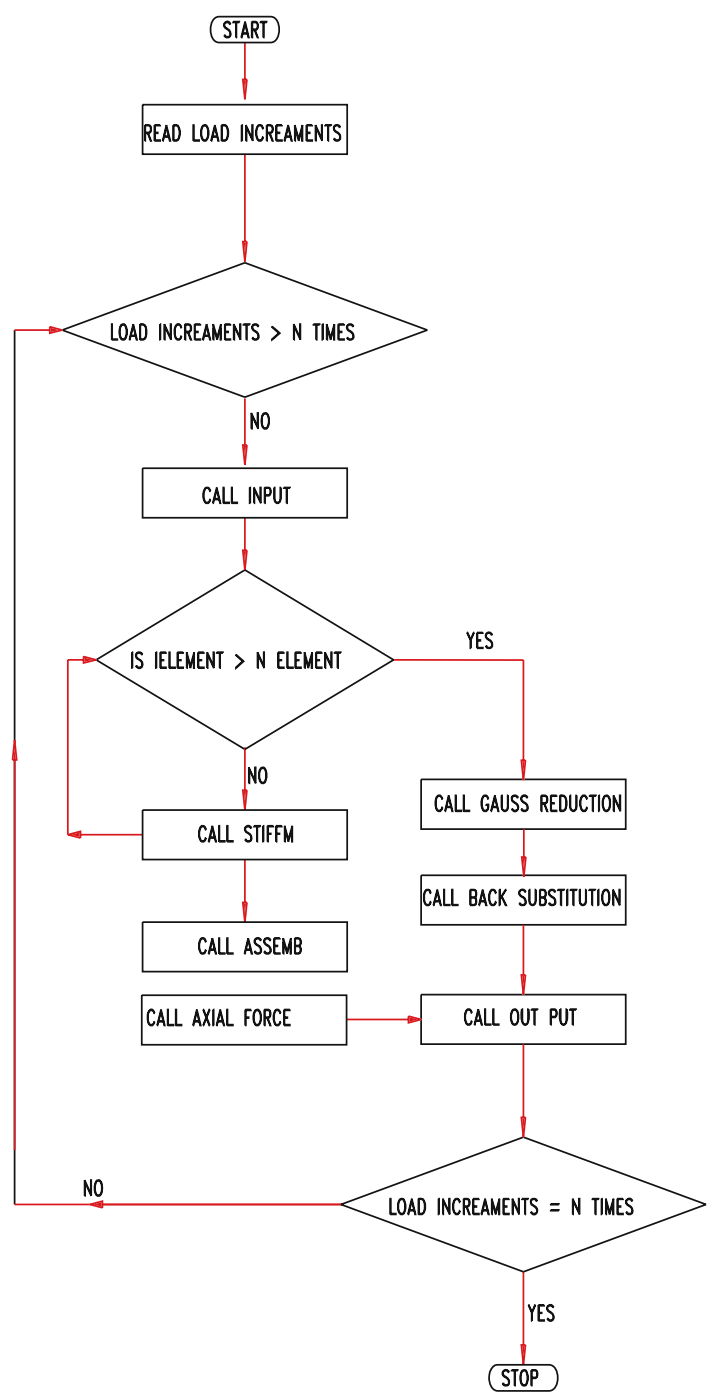

Figure 8. Flow chart of the program.
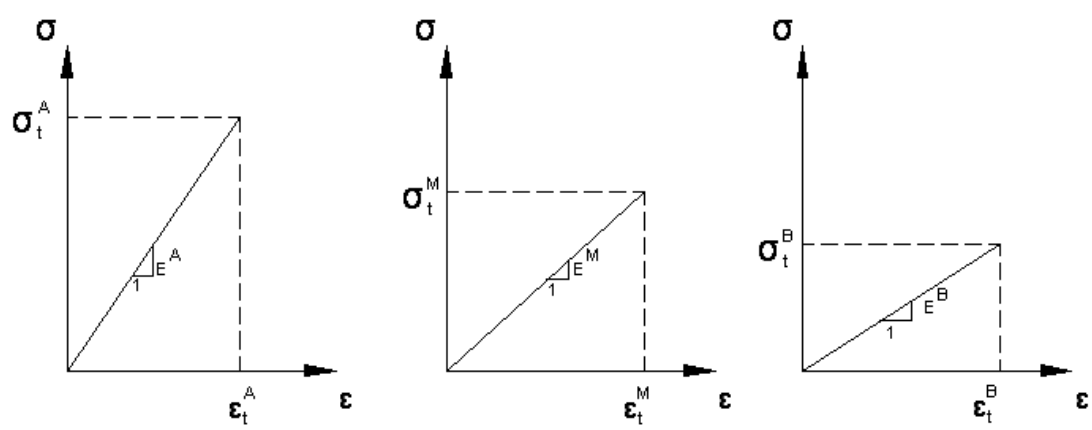

Figure 9. Material models $\left(E^{A}, E^{M}, E^{B}\right.$ are modulus of elasticity for aggregate (A), mortar (M) and bond (B) respectively). 

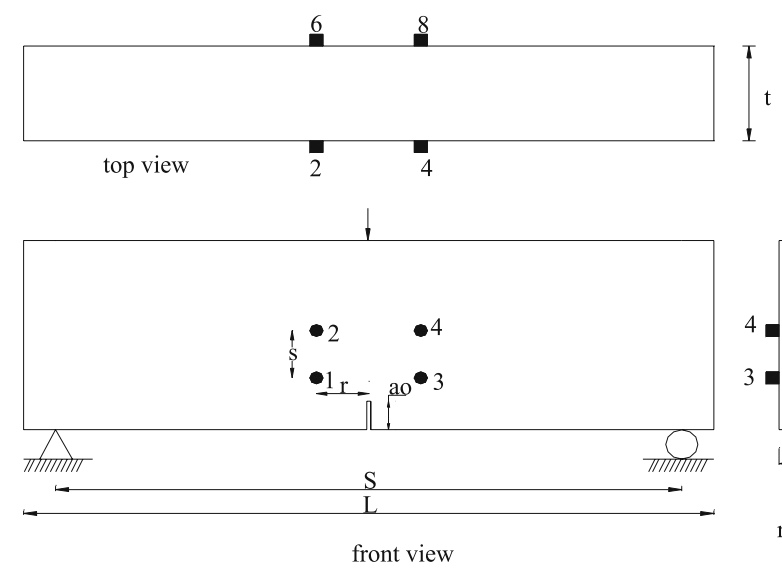

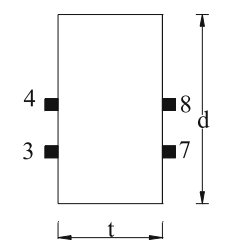

right side view

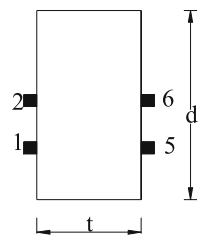

left side view

1 to 8 represents sensors

Figure 10. Schematic diagram of a typical three-point bend specimen [Note: $\mathrm{L}=$ length, $\mathrm{S}=$ Span, $d=$ depth, $\mathrm{t}=$ thickness, $a_{0}=$ notch depth, $\mathrm{r}$ and $\mathrm{s}$ are sensors distances from notch].

(Miller \& McIntire 1987; Ohtsu 1996; Chen Bing \& Liu Juanyu 2004; Lysak 1996; Pollock 1989), a brief review about the literature on AE technique applied to concrete structures is given in this section. Mainly to verify and to evaluate the damage phenomenon that takes place inside a structure when subjected to mechanical loading, the AE technique is useful (Miller \& McIntire 1987; Ohtsu 1996; Pollock 1989). AE belongs to a class of phenomena whereby transient elastic waves are generated by rapid release of energy from localized sources within a material (Miller and McIntire 1987). Researchers in the last few years have been studying fracture and failure of concrete along with acoustic emission technique (Ohtsu 1989, 1996). AE energy is certainly influenced by the micro-structural behaviour, which in turn is influenced by parameters like size and shape of the aggregates, strength of cement matrix, and ratio of the volume of the aggregates to the total volume of the specimen (Landis \& Baillon 2002). It is also known that fracture energy is strongly influenced by the above parameters (Bazant 1998). Researchers have been using AE technique to monitor the state of damage in concrete structures (Colombo et al 2003; Shiotini et al 1999). AE research in civil engineering is in vogue as early as 1960 . The research work up to 1983 was extensively reviewed by (Ohtsu 1989, 1996). Ohtsu reviewed AE research in civil engineering up to 1989 giving more importance to concrete and summarized research activities related AE technique applied to concrete technology with a brief review of historical developments. Mindess (1990) prepared a review of acoustic emission phenomena in concrete. Uomoto (1987) prepared a list of the problems in AE monitoring of concrete structures and presented examples of $\mathrm{AE}$ applications. AE was used to quantify damage in generic laboratory structures for the purpose of tuning damage models (Landis \& Baillon 2002).

\section{Details of experimental program}

\subsection{Materials and specimen preparation}

Schematic diagram of the three-point bend (TPB) test specimen is shown in figure 10 and the same specimen in the experimental set-up is shown in figure 11. In figure 11 depth of the 


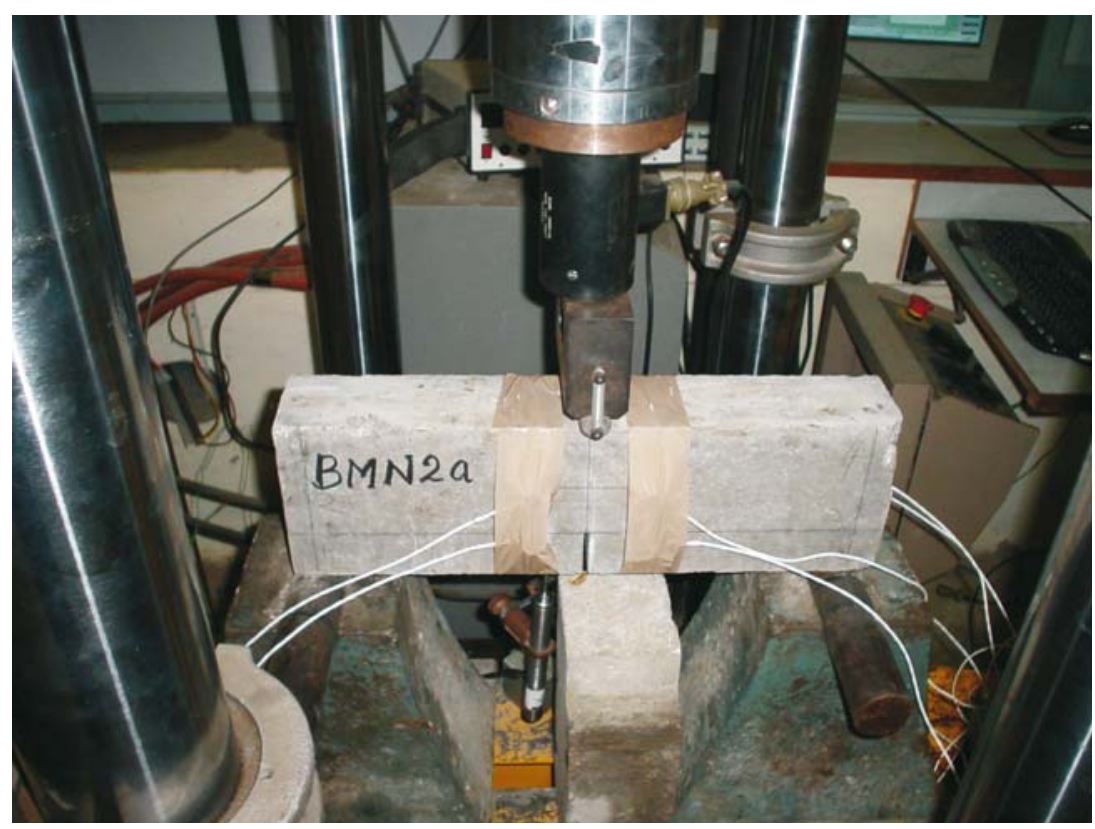

Figure 11. Test beam $(240 \times 80 \times 80 \mathrm{~mm})$ in the experimental set-up.

beam is $80 \mathrm{~mm}$, length of the beam is $260 \mathrm{~mm}$, span of the beam is $240 \mathrm{~mm}$ and thickness of the beam is $80 \mathrm{~mm}$. The specimen is loaded at mid-span and is simply supported over span S. A notch of depth $a_{0}$ is cut into the cured beam. The span-to-depth ratio of the specimen is 3.0. The ratio of notch/depth ratio is $0 \cdot 15$. The notch width is around $7 \mathrm{~mm}$. The TPB specimen thickness is $80 \mathrm{~mm}$. The $28^{\text {th }}$ day compressive strength of the concrete mix used for TPB specimen is $78 \mathrm{MPa}$ and the maximum size of coarse aggregate is $20 \mathrm{~mm}$. The details of the mix proportion are given in table 3 . The concrete specimen required the use of water reducing agent (superplasticizer) in order to increase its workability. Crushed ballast (maximum aggregate size $16 \mathrm{~mm}$ ), portland cement of grade 43 conforming to IS: 8112-1689 and sand are used in the experimental program.

\section{Experimental set-up}

The experimental setup consists of loading frame with data acquisition system and an acoustic emission monitoring system. Three point bend plain (TPB) concrete specimen with (notch/depth) ratio of 3 is tested. The geometric details of the test specimen used in the present experimental study was shown in figure 1. The load frame has a material testing system (MTS) with data acquisition and the specimen is tested under crack mouth open displacement (CMOD) control at the a rate of $0.0004 \mathrm{~mm} / \mathrm{sec}$ and the maximum load was reached in about 5 minutes. The midspan downward displacement was measured using linear variable displacement transducer (LVDT), placed at center of the specimen under bottom of the beam. The AE system used in this present experimental study was a 8 channel AEwin for SAMOS E2.0 developed by physical acoustics corporation (PAC 2005). AE test set-up consists of AE sensors, preamplifiers, processing instrumentation, and SAMOS (Sensor based 


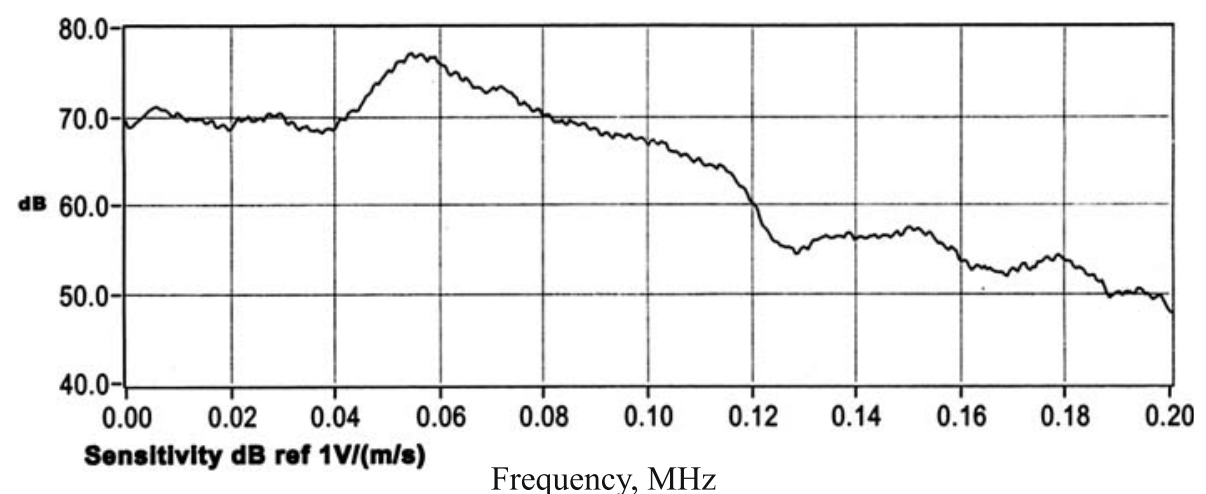

Figure 12. A typical sensor's response as a function of frequency (reprinted with permission from Physical Acoustics Corporation (PAC), NJ, USA, User's Manual SAMOS AE System, 2005).

Acoustic Multi-channel Operating System) AE software. The transducers used in the experimental study were R6D resonant type differential AE transducers with a highest sensitivity at $50 \mathrm{kHz}$ frequency. The diameter of AE sensor is $19 \mathrm{~mm}$ and its height is $22 \mathrm{~mm}$. The AE transducers has peak sensitivity at $75 \mathrm{~dB}$ with reference $1 \mathrm{~V} /(\mathrm{m} / \mathrm{s})$. The operating frequency is $35-100 \mathrm{kHz}$. A typical sensor's response as function of frequency was shown in figure 12 . Vacuum grease LR (high vacuum silicon grease) was used as couplant in the present experimental study. The experimental set-up was shown in figure 11. A clip gauge was used to measure the CMOD. The data acquisition records load, CMOD, mid-span displacement and time. The $\mathrm{AE}$ acquisition system records $\mathrm{AE}$ waveforms and associated event parameters. The $\mathrm{AE}$ signals were amplified with a gain of $40 \mathrm{~dB}$ in a preamplifier. The threshold value $40 \mathrm{~dB}$ was selected to ensure a high signal to noise ratio. In the experimental study the authors obtained AE energy by summing up of all the AE energy release values of 8 channels to get the total AE energy release. It is obvious that the crack propagation starts from the pre-defined notch tip. Therefore the AE transducers are placed near to the notch. The AE energy obtained in the present experimental study are at the specified sensor locations only and sensor location values are presented in table 3 .

Table 4. Concrete mix composition.

\begin{tabular}{lc}
\hline Property & Mix-F \\
\hline Water/binder ratio & $0 \cdot 3355$ \\
Cement, $\mathrm{kg} / \mathrm{m}^{3}$ & $450 \cdot 0$ \\
Micro silica, $\mathrm{kg} / \mathrm{m}^{3}$ & $56 \cdot 25$ \\
Fine aggregate, $\mathrm{kg} / \mathrm{m}^{3}$ & $706 \cdot 955$ \\
Coarse aggregate, $\mathrm{kg} / \mathrm{m}^{3}$ & 1058 \\
Water, $\mathrm{kg} / \mathrm{m}^{3}$ & $150 \cdot 975$ \\
Superplasticiser, $(\%$ of weight of cement present in mix) & $1 \cdot 2$ \\
Compressive strength, $\mathrm{N} / \mathrm{mm}^{2}$ (28-days) & 77.995 \\
\hline
\end{tabular}




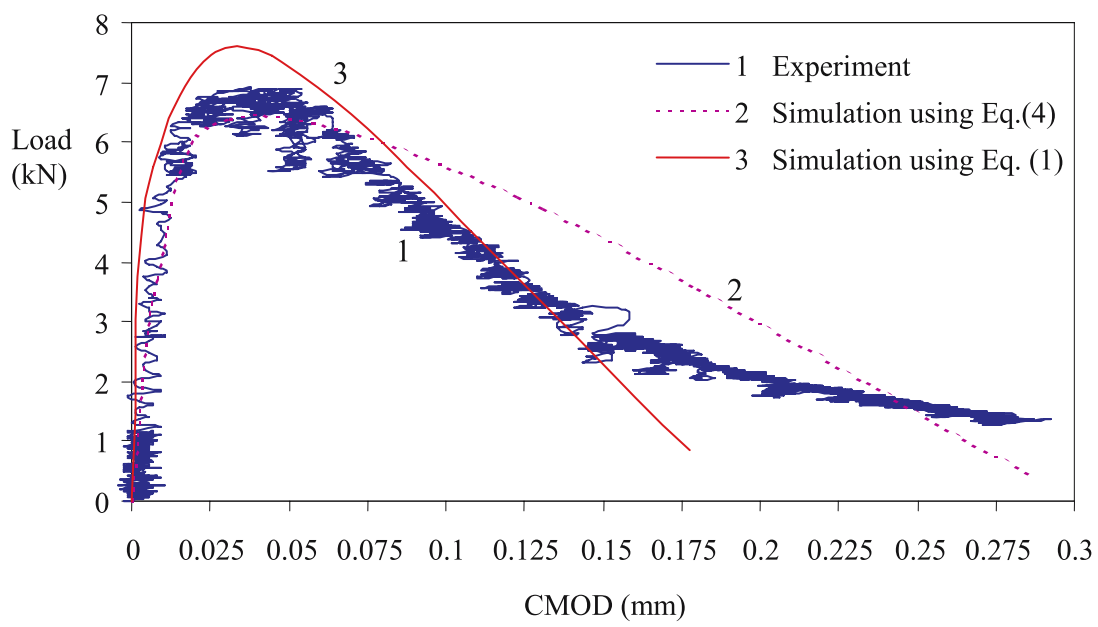

Figure 13. Variation of load with crack mouth opening displacement [Note: Equation (1) represents randomly distributed properties; equation (4) represents generated grain structure following Walraven (1980) and Fuller distribution].

\section{Results and discussion}

A comparison of lattice modelling of concrete fracture results with acoustic emission measurements is of special interest for to understand the capability of the lattice model in

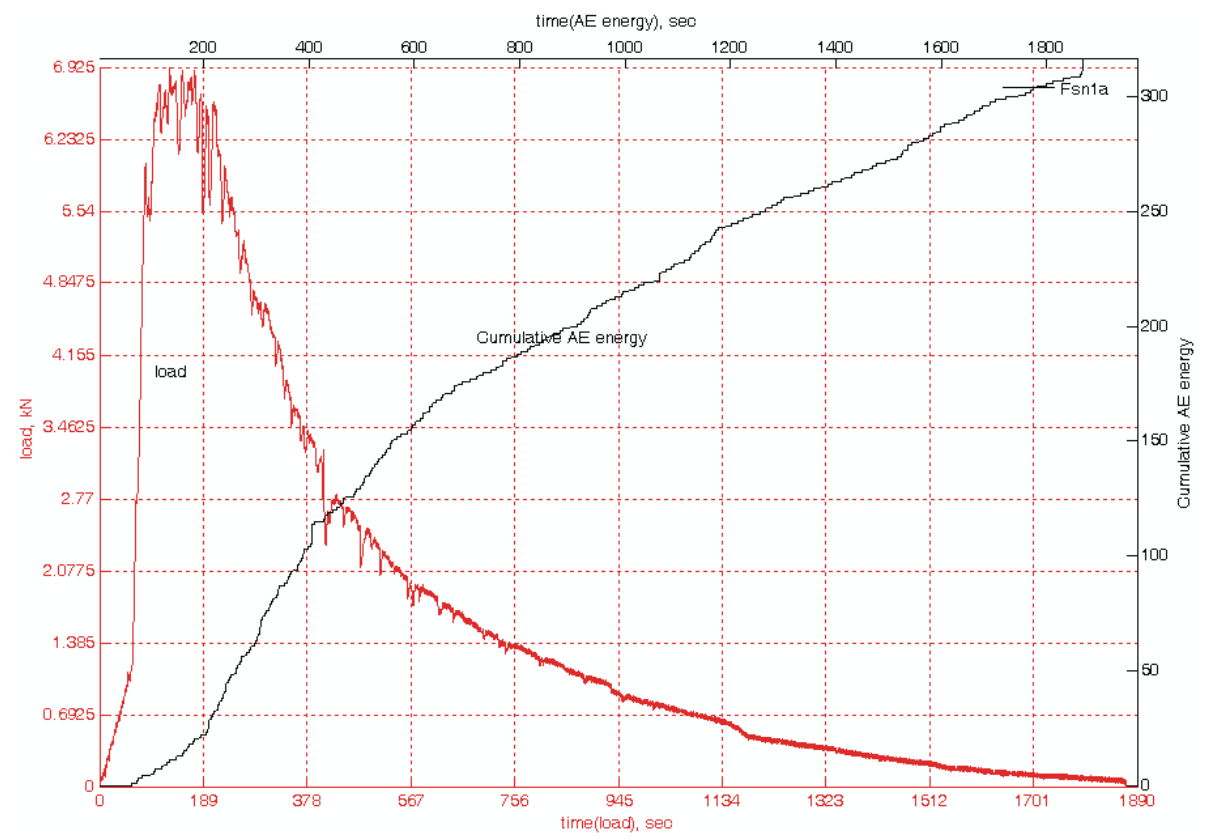

Figure 14. Variation of load and AE energy released with time. 
Table 5. Records of AE measurements.

\begin{tabular}{|c|c|c|c|c|c|c|c|c|c|c|}
\hline & \multicolumn{10}{|c|}{ Time (Sec) } \\
\hline & \multicolumn{2}{|c|}{ Pre-peak zone } & \multicolumn{8}{|c|}{ Post-peak zone } \\
\hline & 75 & 93.7 & 154 & 299 & 475 & 601 & 912 & 1192 & 1219 & 1433 \\
\hline Load $(\mathrm{kN})$ & $3 \cdot 88$ & $5 \cdot 56$ & 6.74 & 4.63 & $2 \cdot 51$ & 1.88 & $1 \cdot 0$ & 0.478 & $0 \cdot 45$ & $0 \cdot 281$ \\
\hline AE hits & 18 & 48 & 183 & 908 & 1823 & 2197 & 2783 & 3000 & 3024 & 3160 \\
\hline Fractured elements & 167 & 879 & 984 & 1054 & 1136 & 1137 & 1145 & 1148 & $* * *$ & $* * *$ \\
\hline
\end{tabular}

predicting the formulation of micro-cracks, both in the pre-peak and in the post-peak regime. The flowchart of the computer program used in the analysis is shown in figure 8. As mentioned earlier, the heterogeneity in the concrete is modelled using (a) assigning randomly distributed material properties to the lattice members, (b) following Fuller's distribution. Plot between load versus crack mouth opening displacement was shown in figure 13. It is interesting to see that crack mouth opening displacement (CMOD) thus obtained from lattice model analysis using the two methods viz. (a) randomly distributed concrete properties and (b) modelling the heterogeneity of plain concrete using generated grain structure following Walraven (1980) fairly agreed with the experimental results. It was observed from the analysis that the bond elements failed first under tensile loading and also the number of fractured elements increased near or after the peak load. The number of fractured lattice elements increases after reaching the peak load. That is the crack starts to propagate. Figure 14 shows the variation of load and cumulative AE energy (in relative units) release with respect to time. The actual units of cumulative AE energy release shown in the figure 14 are volts squared times microseconds, which is proportional to energy. Thus the authors just call it relative units of energy (Landis \& Baillon 2002). From figure 14 one can observe that until the peak load is reached the AE energy accumulated is relatively quite small, which is quite consistent with

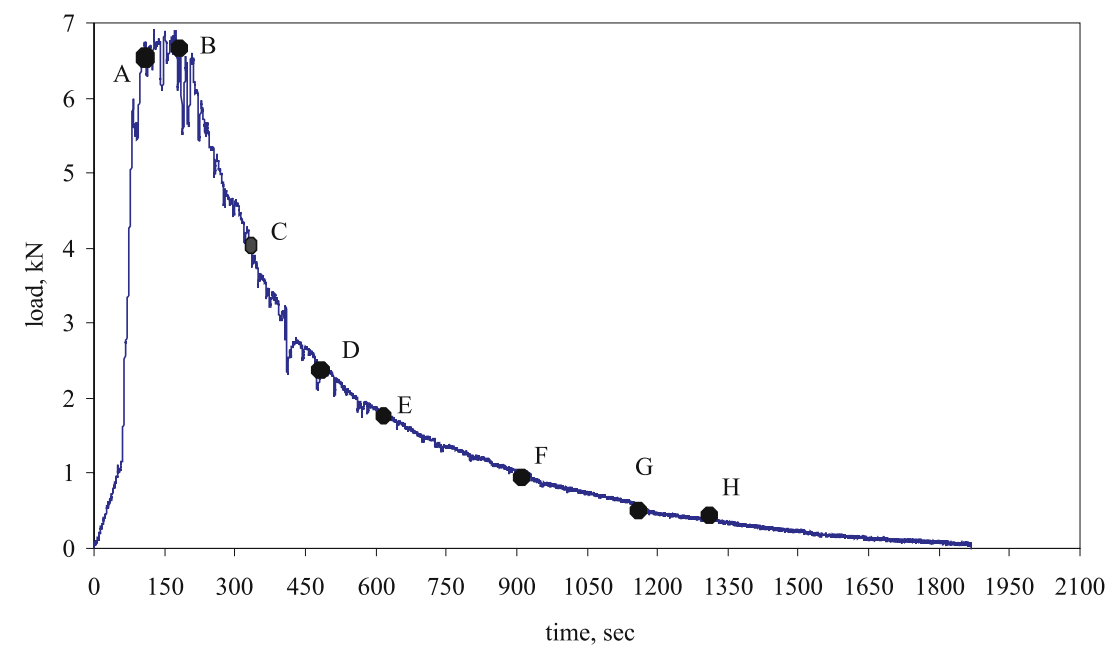

Figure 15. A typical recorded load-time diagram. 
the fact that pre-peak work of fracture is much less compared to that of post-peak particularly when the system is quite pronounced. In other words very little AE activity occurs before peak load. The jump in AE energy release occurs at or near the peak load. The possible reason is the onset of the critical growth. The other observation one can see from figure 14 is that AE energy release rate is high at the peak load. Possibly it indicates that the fracture energy released is maximum at this point. In the present study the fracture energy of the concrete is $180.60 \mathrm{~N} / \mathrm{m}$ and this is calculated following RILEM Committee 50-FMC recommendations 'determination of the fracture energy of mortar and concrete by means of three-point bend tests on notched beams' (RILEM 1985). The AE energy release rate is the slope of the AE energy release curve at the peak load. The increase in release of AE energy after peak-load can be compared with fractured lattice elements. Table 5 shows the load, number AE events occurring during fracture of TPB specimen, time and fracture lattice members. The AE event is a micro-structural displacement that produces elastic waves in a material under load or stress or in other words the AE event may be localized material change which gives rise to the acoustic emissions. It was observed that a number of AE hits took place after the peak load only. Figure 15 shows the locations (indicating particular time and load) where the AE records are compared with the fracture elements in lattice network. Figure 16 shows plots of $\mathrm{AE}$ hits versus time for the tested TPB specimen. It is interesting to see that the number of AE hits taking place near the notch tip of the TPB specimen. Figure 17 shows the recorded $\mathrm{AE}$ events taken place during the test with respect to time. The pattern in which the AE hits are distributed around the notch has the same trend as that of the fractured elements around the notch, which is in support of lattice model. Thus the numerical simulation of concrete fracture using lattice model has been compared with AE activity.

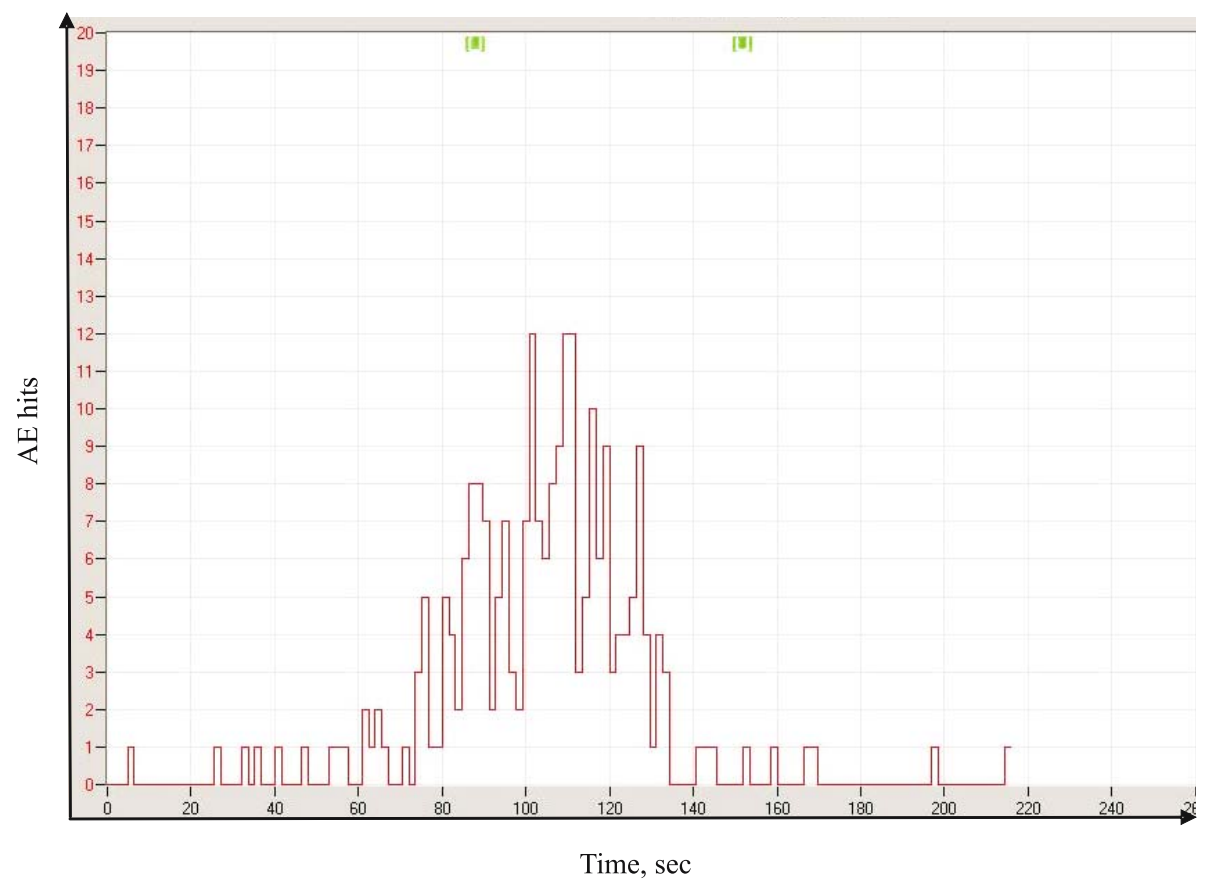

Figure 16. Plot of AE hits versus time for TPB specimen. 


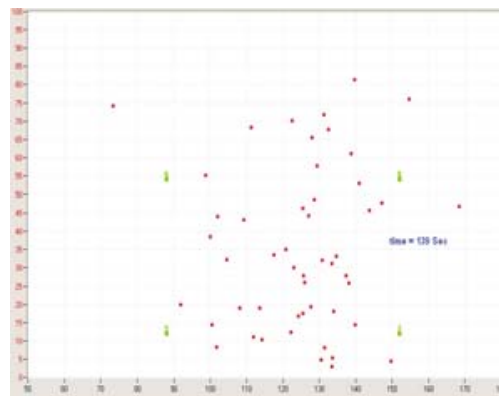

(A)

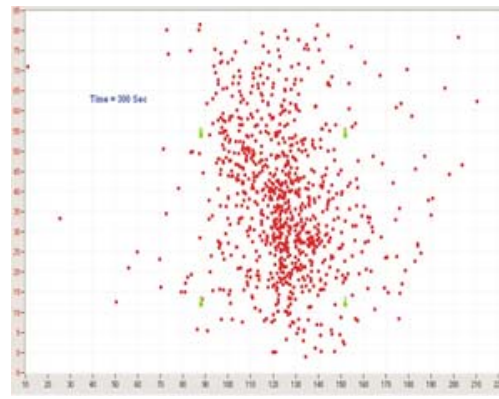

(C)

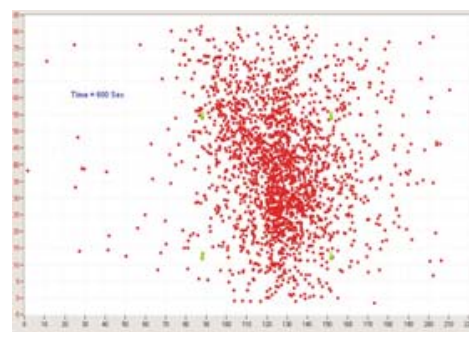

(E)

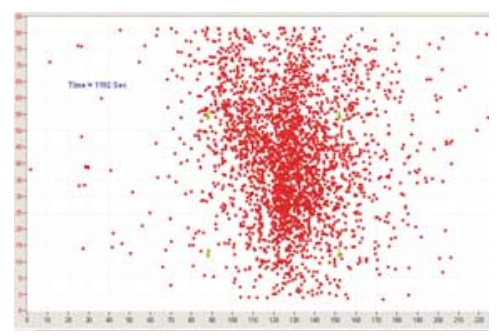

(G)

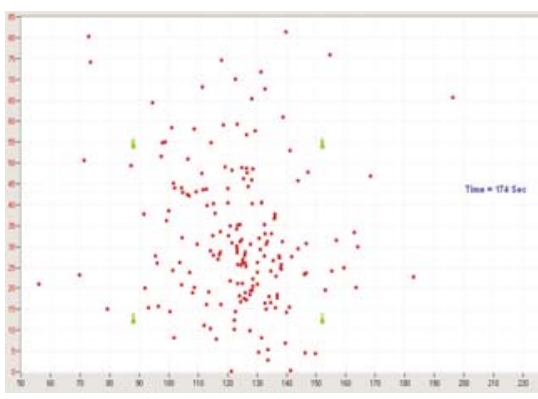

(B)

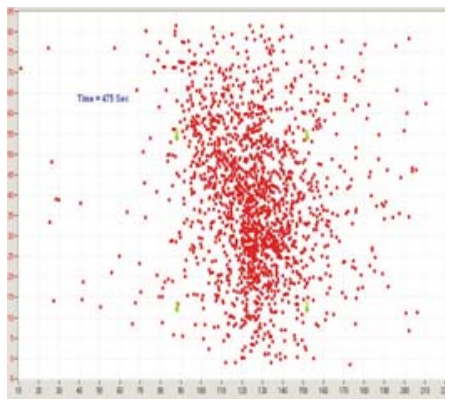

(D)

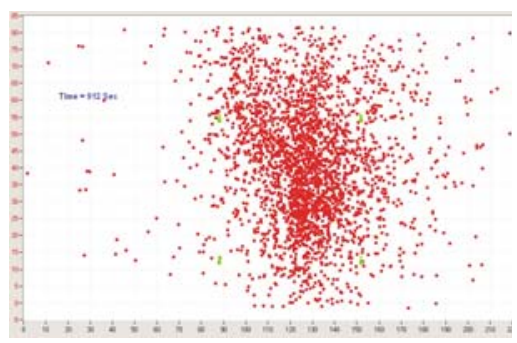

(F)

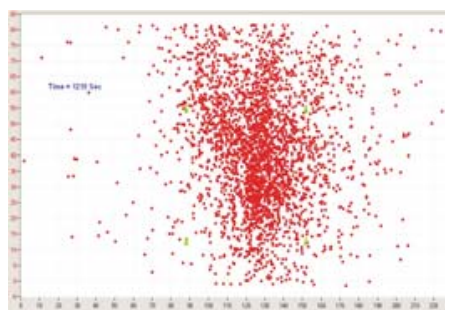

(H)

Figure 17. The AE source locations in TPB specimen tested at time, t: (A) $139 \mathrm{sec}$, (B) $174 \mathrm{sec}$, (C) $300 \mathrm{sec}$, (D) $475 \mathrm{sec}$ (E) $600 \mathrm{sec}$, (F) $912 \mathrm{sec}$, (G) $1192 \mathrm{sec}$, (H) $1219 \mathrm{sec}(X$-axis represents the span and $Y$-axis represents the depth of the TPB specimen tested). 


\section{Conclusions}

In the present work, the lattice modelling technique applicable to concrete fracture studied by earlier researchers has been compared with AE study and also a brief review has been presented about the lattice modelling of concrete fracture. A lattice model at meso level with a simple linear elastic purely brittle failure law in tension was used for simulating the fracture process of a notched plain concrete beam. To compare the numerically obtained results, a TPB specimen was tested under CMOD control and simultaneously acoustic emissions were recorded. The results obtained from simulations with lattice model fairly agree with the experimental results. It is interesting to note that the sequence and quantum of fractured members of the lattice network matches fairly well with the sequence and quantum of AE events.

\section{References}

Alexander K M, Wardlaw J, Gilbert D J 1968 Aggregate-cement bond, cement paste strength and strength of concrete. Proceedings of international conference on the structure of concrete, cement and Concrete Association, 59-81

Arslan A, Ince R, Karihaloo B L 2002 Improved lattice model for concrete Fracture. J. Eng. Mech. ASCE, 128(1): 57-65

Bazant Z P 1998 Fracture and size effect in concrete and other quasi brittle materials. CRC press

Burt N J, Dougill J W 1977 Progressive failure in a model heterogeneous medium. J. Eng. Mech. ASCE, 103: 365-376

Chen Bing, Liu Juanyu 2004 Experimental study on AE characteristics of three-point-bending concrete beams. Cement and Concrete Res. 34: 391-397

Chiaia B Vervuurt, Van Mier J G M 1997 Lattice model evaluation of progressive failure in disordered particle composites. Eng. Frac. Mech. 57(2/3): 301-318

Colombo S, Main I G, Forde M C 2003 Assessing damage of reinforced concrete beam using " $b$-value" analysis of acoustic emission signals. J. Mater. Civil Eng. May/June, 280-286

Herrmann H J 1991 Patterns and scaling in fracture. In: fracture process in concrete, rock and ceramics, J G M Van Mier, J G Rots, A Bakker (eds), Chapman \& Hall/E \& FN Spon, London/New York: 195

Herrmann H J, Hansen A, Roux S 1989 Fracture of disorder elastic lattices in two-dimensions. Phys. Rev. B 39: 637-648

Hrennikoff A 1941 Solution of problems of elasticity by the framework method. J. Applied Mech. (Transactions of the ASME) 8: A169-A175

Hsu T T C, Slate F O 1963 Tensile bond strength between aggregate and cement paste or mortar. J. Amer. Conc. Inst. 4(4): 465-485

Ince R 2005 A novel meso-mechanical model for concrete fracture. Str. Eng. Mech. 18(1): 28-36

Ince R, Arslan A, Karihaloo B L 2003 Lattice modelling of size effect in concrete strength. Eng. Fract. Mech. 70: 2307-2320

Karihaloo B L, P F Shao, Q Z Xiao 2003 Lattice modelling of the failure of particle composites. Eng. Fract. Mech. 70: 2385-240

Karihaloo B L 1995 Fracture mechanics and structural concrete. (New York: Longman Scientific \& Technical)

Landis Eric N, Baillon Lucie 2002 Experiments to relate acoustic emission energy to fracture energy of concrete. J. Eng. Mech. 698-702

Lilliu G van Mier J G M 2003 3D lattice type fracture model for concrete. Eng. Fract. Mech. 70: 7-8: 927-941

Lilliu G 2007 3D analysis of fracture processes in concrete. Ph D thesis, TU Delft, The Netherlands

Lilliu G, van Mier J G M 2007 On the relative use of micro-mechanical lattice analysis of 3-phase particle composites. Eng. Fract. Mech. 74(7): 1174-1189 
Lysak M V 1996 Development of the theory of acoustic emission by propagating cracks in terms of fracture mechanics. Eng. Frac. Mech. 55(3): 443-452

Miller Ronnie K, McIntire Paul 1987 Non-destructive Testing Handbook 5, Acoustic Emission Testing, American Society For Nondestructive Testing INC

Mindess S 1990 Acoustic Emission In: V M Malhotra, N Carino (eds). CRC Handbook on Nondestructive testing of concrete. Boca Raton: CRC Press

Ohtsu M 1996 The history and development of acoustic emission in concrete engineering. Mag. Conc. Res. 48(177): 321-330

Ohtsu M 1989 A review of acoustic emission in civil engineering with emphasis on concrete. J. Acous. Emis. 8(4): 93-98

Pollock A A 1989 Acoustic emission inspection. Technical report, TR-103-96-12/89., Physical Acoustics corporation., 195 Clarksville Road, Princeton Jct., NJ

Physical Acoustic Corporation (PAC) 2005 SAMOS AE system User's manual Rev.2 May

Prado E P, Van Mier J G M 2003 Effect of particle structure on mode I fracture process in concrete. Eng. Fract. Mech. 170: 1793-1807

RILEM Committee 50-FMC 1985 Determination of the fracture energy of mortar and concrete by means of three-point bend tests on notched beams. Mater. Struct. 18(106): 285-290

Roelfstra P E, Sadouhi H, Wittman F H 1985 Numerical concrete. Mater. Struct. RILEM, 18: 327

Sadouki H, VanMier J G M 1997 Meso level analysis of moisture flow in cement composites using a lattice-type approach. Mater. Struct. 30: 579-587

Schlangen E, Garboczi E J 1996 New method for simulating fracture using an elastically uniform random geometry lattice. Int. J. Eng. Sci. 34(10): 1131-1144

Schlangen E, Garboczi E J 1997 Fracture simulations of concrete using lattice models: Computational aspects. Eng. Fract. Mech. 57(2/3): 319-332

Schlangen E, Van Mier J G M 1992a Experimental and numerical analysis of micromechanics of fracture of cement based composites. Cement Concrete Comp. 14: 105-118

Schlangen E, Van Mier J G M 1991 Experimental and numerical analysis of micro mechanisms of fracture of cement based composites, report no. 25.5.-91-1/VFC

Schlangen E, Van Mier J G M 1992b Simple lattice model for numerical simulation of fracture of concrete materials. Mater. Struct. 25: 534-542

Schlangen E 1993 Experimental and numerical analysis of fracture process in concrete. Ph.D Thesis, Delft University of Tech., The Netherlands

Schorn H, Rode U 1987 3-D-modelling of process zone in concrete by numerical simulation, In: S P Shah, S E Swartz (eds.) Proc. SEM/RILEM Int. Conf. Fracture of Concrete and Rock Springer, Wien New York, 220-228

Schorn H, Rode U 1991 Numerical simulation of crack propagation from micro cracking to fracture. Cement Concrete Comp. 13: 87-94

Shah S P, Swartz S E, Ouyang C 1995 Fracture mechanics of concrete: Applications of fracture mechanics to concrete, rock and other quasi-brittle materials, (New York: John Wiley \& Sons, Inc)

Uomoto Taketo 1987 Application of acoustic emission to the field of concrete engineering. J. Acouc. Emis. 6(3): 137-144

Van Mier J G M, Van Vliet M R A 2003 Influence of microstructure of concrete on size/scale effects in tensile fracture. Eng. Fract. Mech. 70: 2281-2306

Van Mier J G M 1997 Fracture process of concrete, Assessment of Material Parameters for Fracture Models. CRC press

Van Vliet M R A 2000 Size effect in tensile fracture of concrete and rock, Ph D thesis, Delft university press, Delft, The Netherlands

Vervuurt A H J M 1997 Interface fracture in concrete. PhD thesis, Delf University of Technology

Walraven J C 1980 Aggregate interlock: a Theoretical and Experimental Analysis. Ph D thesis, Delft University of Technology

William H Press, Saul A Teukolsky, William T Vetterling, Brian P Flannery 1998 Numerical Recipes in Fortran The art of scientific computing second edition, Cambridge University Press

Wittmann F H 1983 Structure of concrete with respect to crack formation In: Fracture mechanics of concrete (ed.) F H Wittmann (Amsterdam: Elsevier) 43-74 